\title{
INVESTIGATION OF AN OUTBREAK OF GASTROENTERITIS
}

\section{DEVELOPMENT OF A PROBLEM}

0 n Tuesday November 26, 1991, 68 children from a public school at Singleton, accompanied by three teachers and six parents, travelled to Hawks Nest. Caravan Park where they were to stay for a week on a camping excursion.

At $1 \mathrm{pm}$ on Thursday November 28 , a local radio station informed the Public Health Unit (PHU) of the Hunter Area Health Service of an outbreak of gastroenteritis among these children. Further information from the Ambulance Service indicated about 20 of the 68 children, who had symptoms of fever, vomiting and diarrhoea, were being taken back to Singleton by ambulance bus. It soon became evident that the campers had been affected by gastroenteritis. Investigation suggested strongly that the outbreak was caused by a viral infection rather than by any water-borne or food-borne source of infection.

\section{INITIAL PHU INVESTIGATION}

A PHU staff member started gathering data which could provide information about the source of the infection. Inquiries revealed:

\section{- groups of children and supervisors were in close proximity during the journey to the camp, daily activities and in their sleeping quarters, so it may be assumed that a considerable amount of interpersonal contact occurred; the school campers all drank water from the caravan park supply. No illness had been reported by other patrons of the park to the Hunter PHU or the New England PHU; and \\ most of the food was transported from Singleton in insulated containers and stored in the coolroom at the caravan park. Only milk and bread were bought at Hawks Nest. The food generally consisted of salads, cooked meat and steak and sausages. Some of the meat was reheated at subsequent meals. Cooking was done on two caravan park barbecues and two barbecues provided by parents.}

At this stage three possible causes of the infection were considered. It was thought that the outbreak may have been caused by contaminated food taken from Singleton, contaminated food bought at Hawks Nest or by a viral infection among the school campers.

\section{COURSE OF THE ILLNESS}

Inquiries revealed that the first case was a boy who became unwell on November 25 - the day before travelling to the camp. He returned home on November 26. His mother reported that she had had symptoms of gastroenteritis just before this, and that members of a neighbouring family had all developed similar symptoms about a fortnight before her son became ill.

Another child became ill with similar symptoms on November 27 and was sent home on November 28 . That day 11 more children complained of the symptoms and a local doctor was asked to examine them. It was decided the sick children should be taken home by ambulance. By the time the ambulance bus arrived at the camp, the number of children with the illness had risen to 22 . Remaining children were escorted home separately on the afternoon of November 28.
General practitioners in all Singleton surgeries were contacted for information about recent cases of gastroenteritis. They reported an unusually high rate of gastroenteritis about three weeks before the school camp, and there were also reports of cases at Singleton Army Barracks.

The 22 children evacuated from the camp by ambulance bus were examined at Singleton Hospital before being allowed home. Symptoms they reported were nausea, vomiting, abdominal pain, diarrhoea, fever and headache. No child was admitted to hospital.

\section{EPIDEMIOLOGICAL INVESTIGATION}

The aim of the exercise was first to identify if the gastroenteritis outbreak was associated with attendance at the camp and second to identify if illness was associated with the consumption of any particular food.

The study population consisted of all pupils and teachers from year 5 and year 6 at the school.

For the purpose of this investigation a person was defined as "ill" if he or she reported symptoms of nausea or vomiting or diarrhoea between November 26 and December 1 . This period extends from the day the school group set out for the camp at Hawks Nest to the third day after they had returned home.

The consent of senior staff in the Department of School Education in the Hunter Region was obtained for the conduct of a survey of relevant staff members and pupils at the school. A letter to parents explained the process and sought permission for the children to fill out the questionnaire.

A list of all foods consumed at the camp was obtained from the teacher in charge, and two questionnaires were constructed. The first, for year 5 children and teachers, included demographic data and questions about symptoms. The second was for year 6 children and teachers. It included the same questions as for year 5 , but added others about food intake during the camp.

The questionnaires were filled out in class on December 4 . Teachers were asked to give the questionnaires to any absent children under similar conditions (i.e. in class) on their return, and then forward the responses to the PHU. The questionnaires were collated and the data analysed using the Epi Info program.

Stool samples were obtained from five of the 22 children but no viral culture tests were carried out.

\section{RESULTS}

It should first be noted that no pathogens were isolated in any of the five stool samples. The outcome of this finding must be interpreted in the light of the analyses of survey data reported below.

There were 71 children in year 5 and 75 in year 6 and three teachers in each year. Questionnaires were returned from 53 year 5 children and 74 year 6 children and their teachers. The response rate for years 5 and 6 was 83.6 per 


\section{Investigation of an outbreak of gastroenteritis}

\section{Continued from page 113}

cent, and the response rate for the campers was 94.9 per cent. Results are described for teachers and pupils together.

The numbers of campers and non-campers who became ill or were unaffected by gastroenteritis are shown in Table 2 .

\begin{tabular}{|llr|}
\hline \multicolumn{2}{|l|}{ TABLE 2} & \\
\hline \multicolumn{2}{|l|}{ THE RISK OF ILLNESS FOR CAMPERS } & \\
\hline III & Camp attendance \\
\hline Yes & Yes & No \\
No & 42 & 9 \\
\hline
\end{tabular}

Odds ratio $=10.11$

(95 per cent $\mathrm{Cl}: 4.25$ to 24.07 )

Thus campers were 10 times more likely to develop gastroenteritis than non-campers. The Yates corrected chi square value was $29.5(\mathrm{p}<0.001)$.

The course of the outbreak over time is illustrated in the histogram representation of the epicurve in Figure 5.

\section{FIGURE 5}

HISTOGRAM REPRESENTATION OF THE

EPICURVE OF THE GASTROENTERITIS OUTBREAK

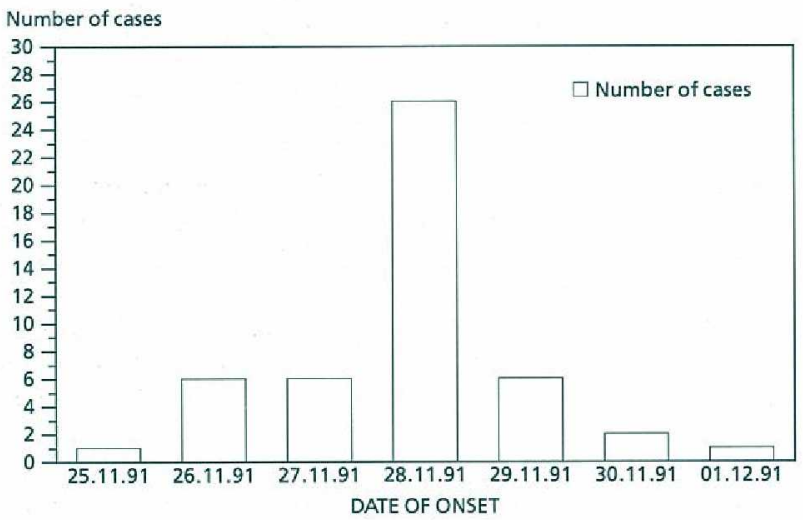

Attack rates were calculated for all 27 foods or drinks consumed from and including dinner on Tuesday to lunch on Thursday.

It was then necessary to examine the association between the consumption of specific foods and illness. Since no food or drink could be identified as an outlier from the attack rates, it was decided to calculate the odds ratios associating coleslaw with illness and lettuce with illness because they were the two foods with the highest attack rates. Odds ratios for all food and drink can be seen in Table 3 .

\section{DISCUSSION}

The highest attack rates were associated with coleslaw and lettuce, both of which have been implicated in outbreaks of food-borne disease in the US. An outbreak of shigellosis in Texas was traced to commercially distributed shredded lettuce (Davis et al, 1988), and two outbreaks of listeriosis have been linked to coleslaw in 41 cases (Schlech et al, 1983) and salads which included celery, tomato and lettuce in 20 cases (Ho et al, 1986). Lettuce has also been identified

\section{TABLE 3}

ODDS RATIOS FOR GIVEN FOODS

\begin{tabular}{lrrr}
\hline Food group & Odds ratio & $95 \% \mathrm{Cl}$ & $\mathbf{P}$ \\
\hline Apple & 0.69 & $0.24-2.00$ & 0.69 \\
Beetroot & 0.80 & $0.26-2.52$ & 0.87 \\
Biscuits & 0.55 & $0.07-3.48$ & 0.70 \\
Bread & 0.00 & $0.00-4.23$ & 0.30 \\
Canned fruit & 0.74 & $0.22-2.39$ & 0.75 \\
Cheese & 1.43 & $0.49-4.61$ & 0.68 \\
Coleslaw & 1.88 & $0.52-7.74$ & 0.43 \\
Cordial & 0.24 & $0.02-1.29$ & 0.11 \\
Corn flakes & 0.77 & $0.25-2.39$ & 0.80 \\
Devon & 0.64 & $0.14-2.70$ & 0.71 \\
Fruit juice & 0.40 & $0.11-1.36$ & 0.17 \\
ce cream & 0.94 & $0.18-4.20$ & 1.00 \\
Jam & 0.41 & $0.09-1.80$ & 0.19 \\
Lettuce & 2.71 & $0.81-9.22$ & 0.12 \\
Margarine & 0.00 & $0.00-2.62$ & 0.29 \\
Milk & 1.22 & $0.32-4.66$ & 0.98 \\
Milkmilo & 0.26 & $0.01-2.41$ & 0.41 \\
Milo & 0.73 & $0.16-3.15$ & 0.75 \\
Orange & 1.23 & $0.38-4.07$ & 0.90 \\
Peanut butter & 0.55 & $0.15-1.95$ & 0.44 \\
Rice Bubbles & 0.58 & $0.18-1.80$ & 0.41 \\
Sausages & 0.86 & $0.15-4.54$ & 1.00 \\
Steak & 4.00 & $0.55-35.39$ & 0.18 \\
Toast & 0.59 & $0.15-2.20$ & 0.55 \\
Tomato & 1.80 & $0.57-5.72$ & 0.38 \\
Tomato sauce & 0.50 & $0.11-2.04$ & 0.43 \\
Vegemite & 1.18 & $0.38-3.68$ & 0.94 \\
\hline
\end{tabular}

Note: using Woolf's procedure (1955). Confidence intervals associated with all remaining odds ratios were calculated using Cornfield's procedure (Cornfield, 1956).

2. The $P$ values each represent the probability of obtaining a particular chi square value (not shown) associated with the contingency table for the given odds ratio. All chi square values were Yates corrected.

as the likely vehicle in the transmission of hepatitis $\mathrm{A}$ in a multifocal outbreak in Kentucky (Rosenblum et al, 1990) and of nonbacterial gastroenteritis among 92 college students in Alabama (Alexander et al, 1986).

The odds ratio for illness in camp attenders of 10.11 with a 95 per cent confidence interval of 4.25 to 24.07 demonstrated that the risk of being affected was at least four times higher for campers than for non-campers.

The two foods with the highest attack rates were coleslaw and lettuce, with rates of 0.72 and 0.71 respectively. The respective odds ratios of 1.88 and 2.71 suggested that the consumption of each food was associated with an increased risk of being affected by gastroenteritis. However the confidence interval in each case showed that no statistically significant association was present.

The food returning the highest odds ratio was steak, with an odds ratio of 4.00 . But the Fisher exact probability value, assessing the extent to which the eating of steak was associated with illness, was not significant. In addition the data indicated that the OR estimate of 4.00 was quite unreliable with a possible "true" value less than 1.00 . Steak was therefore ruled out of contention.

Two facts suggest that water-borne infection was unlikely to be the cause of the outbreak. First, there was no evidence of gastroenteritis among non-school campers using the same water supply. Second, the elimination of lettuce also tends to rule out water which was used for washing the 
D rofessor James S. Lawson, Professor and Head of the School of Health Services Management at the University of NSW, has prepared the following public health items from the literature.

\section{SCREENING OF HEARING LOSS IN HIGH-RISK BABIES}

Severe pre-speech hearing impairment has important consequences in infancy for language acquisition, communication, social and emotional development. Evidence is increasing that even moderate hearing loss in very young children can be detrimental. It is accepted that appropriate remedial measures should be implemented at the earliest possible age and, accordingly, screening for hearing loss in young children is essential.

A sound British study has demonstrated the high reliability in screening for high-risk babies (i.e. babies with familial deafness, rubella infection during pregnancy, very low birth weight, congenital malformations, respiratory difficulties, neonatal jaundice and exchange transfusion). The screening involved measuring the 'electrical' response in the brain stem to sound stimuli. The use of such techniques was found to be highly reliable and cost effective.

McClelland RJ, Watson DR, Lawless V, Houston HG et al. Reliability and effectiveness of screening for hearing loss in high-risk neonates. Br Med J 1992; 304:806-809.

\section{BREAST FEEDING AND HEART DISEASE}

There has been speculation that the high cholesterol and saturated fat content of milk received by infants may influence lipid metabolism throughout life. More than 5,000 men in England who were born after 1911 have been surveyed. Good data are available on whether or not they were breastor bottle-fed during the first year of life. The follow-up, up to 80 years later, has shown there does seem to be a slightly reduced incidence of ischaemic heart disease in those men who were breast-fed compared to those who were bottle-fed during the first year of life. This broad finding is compatible with experiments in animals which have shown that different early feeding can lead to permanent changes in serum lipid concentrations and in the metabolic activity of the enzymes which control cholesterol synthesis and excretion.

Fall CHD, Barker DJP, Osmond C, Winter PD et al, Relation of infant feeding to adult serum cholesterol concentration and death from ischaemic heart disease. Br Med J 1992; 304:801-805.

\section{ANTI-SMOKING CAMPAIGNS REACH LOWER SOCIO-ECONOMIC GROUPS}

A major public health concern in developed countries is the increasing gap in smoking prevalence between groups with different levels of education. In the United States, Canada and Norway smoking in the least educated groups is about twice as prevalent as in the most educated groups and the rate of decline in smoking behaviour is three to nine times lower. During the 1980s mass media-led anti-smoking campaigns were conducted in Sydney and Melbourne and follow-up surveys indicated a significant decline in smoking prevalence. This decline contrasts with the relatively stable smoking levels of the previous decade and has been attributed to the campaigns. There was no evidence that the gap in smoking prevalence between the educational groups increased during the study period in three of the four study groups. The exception occurred among Melbourne women where only the higher educated showed a decline in smoking.

These results are among the first reported examples of a health promotion-motivated behavioural change that did not lead to an increase in the gap between educational levels. They suggest that in previous studies the much larger decreases in smoking prevalence, seen among better educated groups, may have been related to differences in exposure to motivational material rather than to differences in behaviour-changing skills. To continue to address the needs of smokers of all educational levels, the public health movement should conduct anti-smoking campaigns using the full powers of visual mass media.

Macaskill P, Pierce JP, Simpson JM and Lyle DM. Mass media-led antismoking campaign can remove the education gap in quitting behaviour. Am J Public Health 1992; 82:96-98.

\section{TAXES REDUCE CIGARETTE CONSUMPTION}

Many studies have observed that cigarette consumption falls when the price of cigarettes rises. A large American experience conducted over a 33-year period has shown that taxes on cigarettes are associated with a sales decline of tobacco of about 0.5 per cent for every 1 per cent of cigarette price increases. Accordingly, taxes appear to be an effective public health intervention to reduce cigarette consumption.

Peterson DE, Zeger SL, Remingtan PL and Anderson HA. The effect of State cigarette tax increases on cigarette sales 1955 to 1988 . Am J Public Health 1992; 82:94-96.

\section{Investigation of an outbreak of gastroenteritis}

\section{Continued from page 114}

vegetable. Viewed in the light of the questionnaire data, the absence of pathogens in the stool samples would also appear to devalue food as a source of infection.

\section{CONCLUSION}

It was concluded that there was a high probability that the outbreak was not caused by a water-borne or a food-borne infection, but by a viral infection. It was, however, important to initiate a rapid response, both as a field test of established protocol and as an essential data-collecting process which would inform the institution of prospective counter-measures.

\section{Thais Miles, Public Health Officer \\ Victoria Wise, Public Health Officer \\ Michael Leuy, Manager, Infectious Diseases Section NSW Health Department}

Alexander WJ Holmes JR, Shaw JFF Riley WE Roper WL Norwalk virus outbreak at a college campus. South Med.J 1986; 79:33-40. virus outbreak at a college campus. South Med f 1986; 79:33-40. Cornfield JA. Statistical property arising from retrospect Third Berkeley Symp Math Stat Prob 1956; 4:135-148.
Davis H, Taylor JP, Perdu JN, Stelma GN, Humphreys JM et al. Davis H, Taylor JP, Perdu JN, Stelma GN, Humphreys JM et al. lettuce. Am J Epidemiol 1988; 128:1312-1321.

Ho Л, Shands KN, Friedland G, Eckind P, Fraser DW. An outbreak of type $4 \mathrm{~b}$ Listeria monocytogenes infection involving patients from eight Boston hospitals. Arch Intern Med 1986; 146:520-524.

Kahn HA and Sempos CT. Statistical methods in epidemiology. New York: Oxford University Press, 1989.

Rosenblum LS, Mirkin IR, Allen DT, Safford MD, Hadler SC. A multifocal outbreak of hepatitis A traced to commercially distributed lettuce $A J P H 1990 ; 80: 1075$-1080.

Schlech WF, Lavigne PM, Bortolussi RA et al. Epidemic listeriosis: Schlech WF, Lavigne PM, Bortolussi RA et al. Epidemic listeriosis: evidence for transmission by food. N Engl J Med 1983; 308.203-206. Ann Hum Genet 1955; 19:251-253. 